\title{
Opioid Peptides, CRF and Urocortin in Cerebrospinal Fluid-Contacting Neurons in Xenopus laevis
}

\author{
MARINELLA CALLE ${ }^{1}$, ILSE E.W.M. CLAASSEN ${ }^{1}$, JAN G. VEENING ${ }^{2}$, TAMAS
}

KOZICZ ${ }^{1}$, ERIC W. ROUBOS ${ }^{1}$, HENK P. BARENDREGT ${ }^{3}$

${ }^{1}$ Department of Cellular Animal Physiology, Nijmegen Institute for Neurosciences,

Faculty of Science, Radboud University Nijmegen, ${ }^{2}$ Department of Neuroanatomy and

Embryology, University Medical Centre, ${ }^{3}$ Department of Computational Sciences,

Faculty of Science, Radboud University Nijmegen; Nijmegen The Netherlands

Running title: Peptides in CSF-contacting neurons in Xenopus

Address for correspondence: Marinella Calle, Department of Cellular Animal Physiology, Radboud University Nijmegen, Nijmegen, Toernooiveld 1, 6525 ED Nijmegen, The Netherlands

mcalle@science.ru.nl

\begin{abstract}
The presence of the opioids $\beta$-endorphin, met-enkephalin and endomorphin and of corticotropin-releasing factor (CRF) and the CRF-family member urocortin (Ucn) is described in cerebrospinal fluid-contacting neurons in the brain of the amphibian Xenopus laevis.
\end{abstract}

KEYwORDs: opioids; CRF; urocortin; cerebrospinal fluid, Xenopus laevis

\section{INTRODUCTION}


Intercellular communication in the brain can be divided into two types: wiring transmission, via synaptic contacts, and volume transmission, by the diffusion of chemical messengers via the intercellular space or the cerebrospinal fluid (CSF). Since communication via the CSF is a relatively slow process, volume transmission may particularly control delayed-onset processes like emotion and stress adaptation (1). Various peptides have been implicated in such processes, like opioids (2) and peptides from the corticotropin-releasing factor (CRF) family (3). One of the intriguing questions as to volume transmission concerns the mechanism by which such neuropeptides are released into the CSF. Likely candidates are dendrites of CSF-contacting neurons (CSFen), which occur throughout the vertebrate phylum but are particularly numerous in lower vertebrates (4). Here we describe the presence of the opioids $\beta$-endorphin, met-enkephalin and endomorphin and the CRF-family members CRF and urocortin (Ucn) in CSFen in the brain of the amphibian Xenopus laevis.

\section{MATERIAL AND METHODS}

Xenopus laevis (aged 6 months), reared under standard laboratory conditions were anaesthetised and brains were processed for light and immuno-electron microscopy using high-pressure freezing and cryosubstitution, as described elsewhere $(5,6)$. Primary antisera were against rat met-enkephalin, $\beta$-endorphin and endomorphin, all raised in rabbit (dilution 1:1,000), Xenopus CRF (dilution 1:15; R.J. Denver, Ann Arbor, MI, personal communication; the CRF serum was his generous gift) and rat Ucn (1:30,000; generous gift from Dr J. Vaughan, La Jolla, CA). No immunopositivity was observed when a first antiserum was omitted from the reaction. All studies were performed under the guidelines of the Dutch law concerning animal welfare.

\section{RESULTS AND DISCUSSION}

$\beta$-Endorphin. Immunopositive CSFen were observed in the caudal part of the 
suprachiasmatic nucleus (SC), in the paraventricular organ $(\mathrm{PVN})$ and in the ventral hypothalamic area. They send their dendritic processes in between the ependymal cells to the CSF (Fig. 1a).

Met-enkephalin. Some immunoreactive CSFen were seen in the SC and in the tuberculum posterior, showing long, slender dendritic processes that contact the CSF (Fig. 1b).

Endomorphin. Numerous moderately positive CSFen are present in the SC (Fig. 1c), some of them located directly beneath the ependymal cell layer of the ventricle and protruding with their dendrites into the CSF.

$\boldsymbol{C R F}$. A few immunopositive CSFen occur in the SC and numerous immunoreactive CSFen are present in the PVN. Some show short dendrites that run towards the ventricle, passing through the ependymal layer to contact the CSF (Fig. 1d).

Ucn. Numerous immunoreactive CSFcn are situated in the anterior preoptic nucleus. They are small, piriform or fusiform, and their processes run in between the ependymal cells to contact the CSF. In the SC, many small, strongly stained CSFcn are situated near the border of the ventricle. They generally are fusiform, with many ramifying dendrites contacting the CSF (Fig. 1f).

Our immunocytochemical data show that both opioids and members of the CRFpeptide family are present in CSFcn in the brain of Xenopus laevis, including in their dendrites. The ventricular location of these dendrites strongly suggests that the peptides are released into the CSF. We assume that the peptides are transported via the CSF to other parts of the ventricular system to become either bound to selective receptors in neuronal elements located in the ventricular wall or to diffuse into the brain to control specific targets situated at some distance from the CSF.

\section{REFERENCES}

1. Roubos, E.W., W.J.J.M. Scheenen \& B.G. Jenks. 2001. Neuroendocrinology - from concepts and complexity to integration. In: Perspective in Comparative 
Endocrinology: Unity and Diversity (H.J.T. Goos, R.K. Rastogi, H. Vaudry, R. Pierantoni, Eds). pp. 465-472. Monduzzi Editore, Bologna.

2. Herckenham, M. 1991. Mismatches between neurotransmitters and receptor localization: implications for endocrine functions in brain. In: Volume transmission in the brain: novel mechanisms for neural transmission. (H. Fuxe and L.F. Agnati, eds.). pp. 63-87. Raven Press, Ltd., New York.

3. Rothman, R.B., N. Vu, H. Xu, et al. 2002. Endogenous corticotropin releasing factor regulates adrenergic and opioid receptors. Peptides. 23: 2177-2180.

4. Vigh, B., M.J. Manzano e Silva, C.L. Frank, et al. 2004. The system of cerebrospinal fluid-contacting neurons. Its supposed role in the nonsynaptic signal transmission of the brain. Histol. Histopathol. 19: 607-628.

5. Kramer, B.M.R., I.E.W.M. Claassen, N.J. Westphal, et al. 2003. Alphamelanophore-stimulating hormone in the brain, cranial placode derivatives, and retina of Xenopus laevis during development in relation to background adaptation. J. Comp. Neurol. 456: 73-83.

6. Wang L.C., H.K. Meijer, B.M. Humbel, et al. 2004. Activity-dependent dynamics of coexisting brain-derived neurotrophic factor, pro-opiomelanocortin and $\alpha$ melanophore-stimulating hormone in melanotrope cells of Xenopus laevis. J. Neuroendocrinol. 16: 19-25.

\section{Legend}

FIGURE 1. CSFen in the Xenopus laevis brain, immunopositive to $\beta$-endorphin in SC (a), met-enkephalin in SC (b), endomorphin in SC (c), CRF in PVN (d) and Uen in SC (e). Arrows point to dendrites contacting the CSF. Bar $=20 \mu \mathrm{m}$. 